His first principle, that the primary object of every county museum should be to make as perfect a collection as possible of the natural productions of that county, exhibited in the most attractive form, is undoubtedly correct, and has been definitely sanctioned by a large body of competent authorities. This is just what can be done by each provincial museum better than by any other institution in the world, and it is just what is especially wanted by scientists, by students, and by the public. But this unfortunately has not been made the primary object either at Leicester, Nottingham, or Derby.

Mr. Sharpe's second principle, that each museum should possess also a typical series of foreign specimens for comparison with the local ones is equally correct. Science depends upon the appreciation of similarities and differences. The faculty of careful observation and comparison is of such fundamental value in all education and might be so effectively cultivated in museums that these institutions will in the future be found essential adjuncts to the schools. But here all existing museums are particularly weak. Opportunities for comparison are not sought out. The collections are not arranged with any special view to making comparisons easy and obvious. If, for instance, the local birds are in one room, and the foreign types in another, comparison is made as difficult as possible. Even if they are on opposite sides of one gallery, and the divisions of the orders made exactly to correspond, it is still difficult. They must be brought so near together that the eye can match them as it would match two patterns. This can be accomplished, and in an artistic and very interesting manner. It is to be hoped that the museum of the future will work out Mr. Bowdler Sharpe's principles much more completely than has yet been done.

Birstal Hill, Leicester

F. T. MotT

\section{Measuring Heat}

DURING the past twelve months I have been endeavouring to construct some form of calorimeter which should aid me in the identification of minerals, and which should, to that end, combine accuracy with ease of manipulation. The avoidance of thermometry seemed highly desirable, and a differential method suggested itself.

One gramme of the mineral undergoing investigation, and one gramme of pure silver, are heated in the same steam chamber and simultaneously transferred into the muffles of two Favre and Silbermann's calorimeters, made of uniform size and placed side by side, similarly shielded from external sources of error during experiment. The specific heats are compared by the index movements of the calorimeters, the index tubes being either simply calibrated or empirically graduated.

Both calorimeters are here exposed to the same external sources of error. The amount of heat lost by radiation, however, will, for each calorimeter, depend on the duration of the experiment and the rise of temperature experienced. Now the heat received is communicated to the walls of the calorimeters by convection currents, ascending from the muffles, in the first instance, very much more slowly by conduction. It appeared, then, that an internal non-conducting shield of a porous nature lining the walls and retarding convection currents might reduce such loss very considerably. Experiment confirmed this supposition. An apparatus I have had constructed on this principle by Yeates of Dublin is now nearly ready for experiment.

\section{Engineering School, Trinity College, Dublin,} August 5

\section{Circular Rainbow seen from Hill-top}

THIs is not such an unusual phenomenon. It depends of course on the position of the observer as regards the sun, and his "coin of vantage," viz. having a space below him. I have seen it several times in my life, and remember a beautiful illustration of it given by Mr. Bains, the artist who accompanied the traveller Chapman to the Victoria Falls on the Zambese. His painting was, and probably is, in the Library at Cape Town. $\mathrm{He}$ is represented as standing on a projecting rock overlooking the Falls, or perhaps I should say looking up the crevice into which the water falls, and in the centre of a glorious double circular rainbow. I have heard the picture much criticised and it accuracy doubted, but having had actual experience of such a sight, I always maintaned its correctness.

I saw lately another "bow," which struck me as very remark- able-perhaps because I never saw one like it before. My house stands on a hill-top; below me at some distance is a piece of low ground, covered by the tide at high water. The sun was low behind me, and the "bow" was formed on a mist coming up from the sea and swamp. It was, however, so flat that it at once arrested my attention, and I called the members of my family to see a "flat rainbow"! All agreed they had never seen onc like it. It was quite near us, as was proved by its intervening between certain objects; but I subsequently detected one part a long way to the left of me, showing it was, of course, a true "bow", but of an enormous size.

British Consulate, Noumea, June I 7

E. L. LAYARD

\section{THE MIGRATION OF SALMON}

DRING the last ten years some exceedingly interesting researches have been effected by German, Finnish, Swedish, and Norwegian ichthyologists as to the migration of salmon on their respective coasts. Thus, by careful researches, some Swedish and Finnish savants have proved that the salmon, which in the summer are caught in the rivers of the upper gulf of the Baltic, have at another season, most probably in the winter, paid a visit to the shores and rivers of Northern Germany. This has been conclusively proved by salmon caught in the Swedish and Finnish rivers having German-made hooks in their gills and stomach. From this it is therefore apparent that, in the Baltic, salmon are in the habit of quitting the rivers of Northern Sweden and Finland in the autumn in order to visit the shores of Northern Germany during the winter, and return to their haunts in the spring. That the fish should be capable of performing the enormous journey across the Baltic--from the upper gulf to the Pomeranian coast--and back every year may indeed seem incredible, but that it is impossible is fully disproved by the experiments with salmon and trout effected by the late Mr. Fraik Buckland on the coasts of Scotland and England in the same direction.

In March 1872 Profs. Virchow and Hansen were commissioned by the German Fishery Association to "mark" some of the salmon which had been hatched artificially near Hameln, in order to ascertain whether they were in the habit of returning to the river. The fish then in the hatching reservoirs were one year old, and mostly seven centimetres in length, although some were twice the size. Having tried cutting off various parts of the fins, it was found that it was most suitable for the object in view and the health of the fish to cut the so-called "fat" fin right away, particularly as the fish would retain this mark even when full grown.

On March 23 and 24, I872, a thousand salmon marked in this manner were let out into the Weser. The marking was effected by taking the fish in the left hand, and then cutting the fin away with a pair of scissors, whereby the fish were perfectly uninjured. The little fat fin, which is mostly found on Salmonidæ only, contains no nerves of any importance, and has no particular function, so that its removal does not impair the fish in the least.

Ever since that year the fishermen between Bremen and Hameln have been on the look out for the marked fish, but not until a month ago a fish was caught, weighing 30 lbs., at Osterdeich, just above Bremen. The fat fin, which, on the fish one metre long, ought to have been six centimetres, was entirely absent; and, when the wellhealed cut was felt, the hard membrane indicated that an operation had at one time or another been performed at this spot. The fish, which was marked as a grilse in 1872 , was then thirteen years old -an age which in every respect corresponds with the age fixed by the fishermen. According to general observation, it has been demonstrated that the salmon in the Weser is, when one year old, from five to twelve centimetres long. In the second year it has been proved that the salmon go into the sea, and when they re-enter the river at four years of 
age they weigh from eight to twelve pounds, and in the fifth year from twelve to fifteen pounds. From that age upwards the weight increases rapidly.

The results of the artificial hatching in the Weser are exceedingly promising. Thus the salmon fisheries at Hameln have been doubled in consequence during the last ten years, the tax at present paid to this town alone by the salmon fisheries being more than a thousand pounds.

In Norway, too, efforts have been made in the same direction during the last few years. Thus in 1883 the Storthing granted a sum of money for this purpose, and with this amount the Chief Inspector of Fisheries, Herr A. Landmark, has effected the marking of several hundreds of salmon and trout, chiefly on the west coast of Norway, during last autumn and winter. The marking here is effected by means of a tiny bit of platinum, $7 \mathrm{~mm}$. long, and $4 \mathrm{~mm}$. broad, being thus about the size of the nail on the little finger, which is attached by a very fine platinum wire to the fat fin of the big fish and the tail of the smaller ones. The piece has a number stamped on it, which corresponds with one in a "log" giving all the particulars as to the date the fish was marked, its weight, size, \&c.

In order to encourage fishermen to be on the look-out for these marked fish, the inspector offers a reward of two shillings and sixpence for each mark forwarded to him, if accompanied with precise information as to the spot and date when it was taken, the length and breadth of the fish, and its weight.

As these researches will tend greatly to ascertain the habits and migrations of Salmonida, the result will be watched with interest.

\section{THE TRINITY HOUSE EXPERIMENTS ON LIGHTHOUSE ILLUMINANTS}

THE great advances made during the past few years in the science of illumination have rendered it desirable, or rather absolutely necessary, that experiments should be undertaken with a view to the determination of the advantages and disadvantages attending the use of different illuminants in lighthouses. With this view the Corporation of Trinity House have commenced a series of experiments at the South Foreland.

There are at present on the South Foreland two lighthouses, known as the high light and low light, and both of these are illuminated by electricity. Near these, three experimental lighthouses have been erected for use with the electric light, with gas and with oil respectively. The electric apparatus consists of three arc lamps and three magneto-electric machines made by Baron de Meritens. The lamps are placed one above the other in the tower. The carbons being used are "compound carbons," made up of many small rods of carbon of square section, coated with copper, and Siemens's "core-carbons," made of gas-carbon, with a central rod of graphite. When worked up to their full power, each lamp is estimated to be capable of giving a light equal to 30,000 candles.

The second tower is fitted up with Mr. Wigham's gasburners. To supply the burners a small gasworks, fitted with retorts, purifiers, and a gasholder capable of holding about 5000 cubic feet, have been erected near by. The tower contains four burners, one above the other, each burner consisting of concentric rings of jets. The total number of jets on each burner is Io8, making a total on the four burners of 432 jets; but the outer rings may be removed when less light is required: so that each burner may be used with $28,48,68,88$, or Io 8 jets. A talc chimney above the flame produces the necessary draught; no glass or talc is placed over the most luminous portion of the flame.

The intensity of the light when all the jets on all four burners are used is stated by the inventor to be equal to
12,000 candles. The third tower is for the present devoted to the oil and gas-burners invented by Sir James Douglass. The oil is supplied from a tank to the burners under a slight pressure. One oil-burner has six concentric wicks, and has a power of 720 candles ; a second has seven wicks and a power of 1000 candles. There are three burners in the tower, placed one above the other. Each tower is provided with lenses both for revolving and for fixed lights. The highest power of the gas tower is a quadriform light, of the other towers a triform light. Besides the illuminants already mentioned, there are gas-burners from the Sugg and from the Siemens Companies, which will be tested in the lighthouse towers.

For observing the lights and testing them, a line of

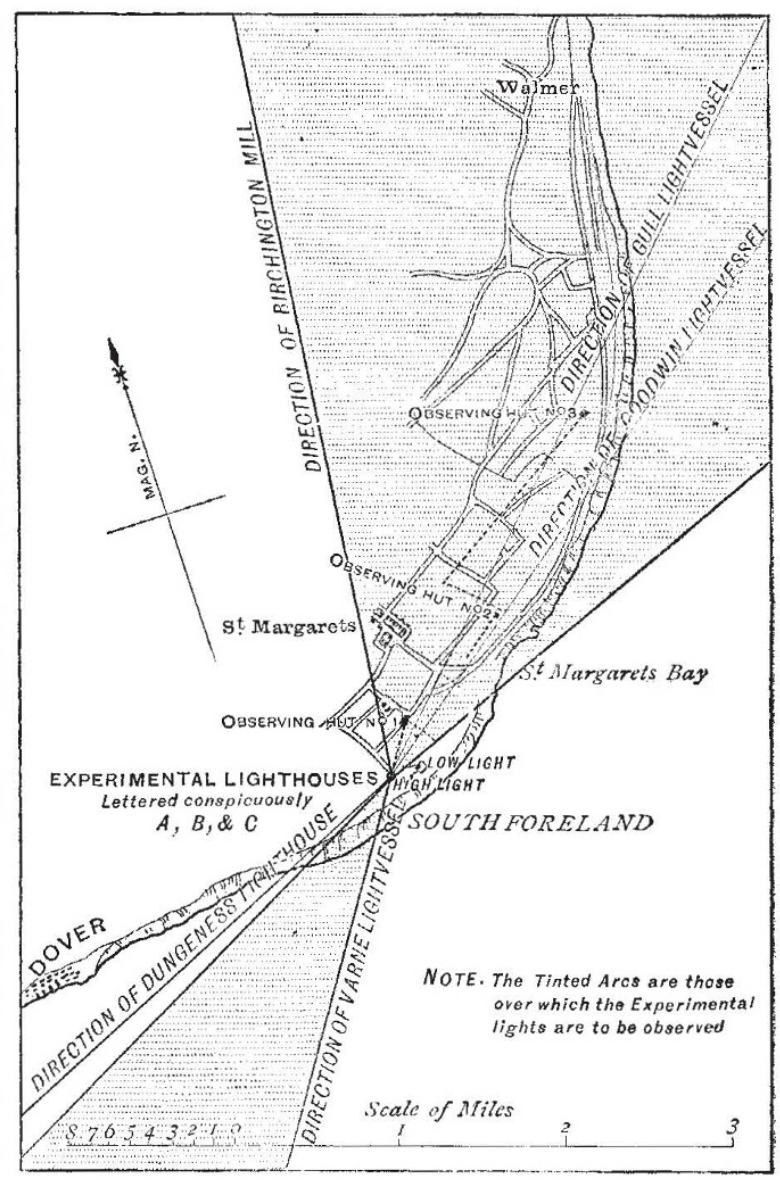

Local Map for Observations on Land.

observation has been measured out in the direction of Deal, and three huts have been erected at a distance of $\frac{1}{2}$ mile, $1 \frac{1}{4}$ mile, and $2 \frac{1}{2}$ miles respectively from the towers. These huts are fitted up as photometric observatories. The lights are focussed on one of the huts, and they are then measurcd in all conditions of weather by means of the pentane unit of light devised by Mr. Vernon Harcourt. When the weather is too thick to allow of direct comparison with the unit, the lights are compared one with another by means of a polariscope-photometer, in which the ordinary image of one light is brought to equality by means of a Nicol prism with the extraordinary image of another light. In ordinary weather a ray from the lighthouse tower enters a hole in a shutter and falls 